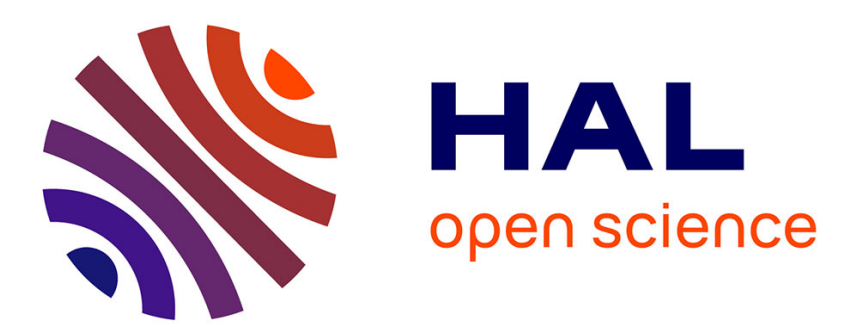

\title{
Locally Enhanced Dissolution Rate as a Probe for Nanocontact-Induced Densification in Oxide Glasses
}

\author{
Yi-Fan Niu, Kun Han, Jean-Pierre Guin
}

\section{To cite this version:}

Yi-Fan Niu, Kun Han, Jean-Pierre Guin. Locally Enhanced Dissolution Rate as a Probe for Nanocontact-Induced Densification in Oxide Glasses. Langmuir, 2012, 28 (29), pp.10733-10740. 10.1021/la300972j . hal-00829987

\section{HAL Id: hal-00829987 https://hal.science/hal-00829987}

Submitted on 14 Aug 2020

HAL is a multi-disciplinary open access archive for the deposit and dissemination of scientific research documents, whether they are published or not. The documents may come from teaching and research institutions in France or abroad, or from public or private research centers.
L'archive ouverte pluridisciplinaire HAL, est destinée au dépôt et à la diffusion de documents scientifiques de niveau recherche, publiés ou non, émanant des établissements d'enseignement et de recherche français ou étrangers, des laboratoires publics ou privés. 


\title{
Locally Enhanced Dissolution Rate as a Probe for Nanocontact- Induced Densification in Oxide Glasses
}

\author{
Yi-Fan Niu, ${ }^{\dagger, \ddagger}$ Kun Han ${ }^{\dagger}$ and Jean-Pierre Guin ${ }^{* \dagger, \S}$ \\ ${ }^{\dagger}$ LARMAUR ERL-CNRS 6274, University of Rennes I, France
}

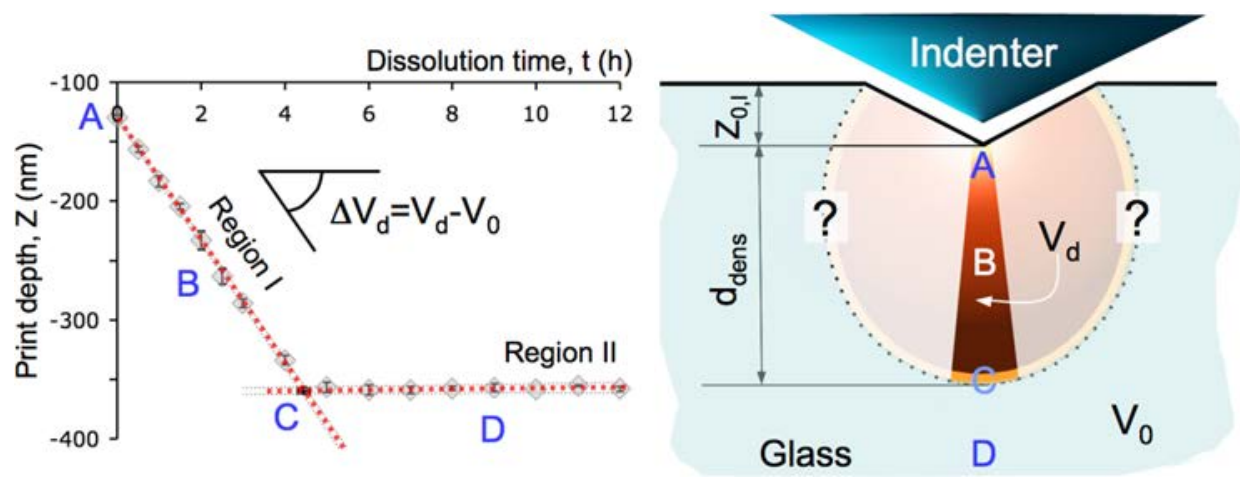

\begin{abstract}
Atomic force microscopy (AFM) was used to characterize the surface damage (nanoindentations) effect on the chemical durability of glass surfaces (silica and soda-lime silicate glasses, WG). In basic solutions, an enhanced dissolution rate is reported and quantified at indentation sites $(+10.5 \mathrm{~nm} / \mathrm{h}$ and $+52 \mathrm{~nm} / \mathrm{h}$ for silica and WG, respectively) whereas none was observed once the indented surfaces were thermally annealed at $0.9 \times T_{\mathrm{g}}$ for $2 \mathrm{~h}$, a thermal treatment known for curing high pressure-induced permanent densification in oxides glasses. A direct link between high pressure-induced structural modifications encountered during nanoindentation and the measured dissolution rates is established. It is shown that this property conjointly used with the high resolution of the atomic force microscope may be used for probing, at the nanometer scale, the size and the nature of the structurally modified area underneath residual nanoindentation impressions. As an example, for $10 \mathrm{mN}$ Vickers nanoindentations on WG, the zone affected by the permanently and structurally modified zone under the residual impression is found to be equal to $(741 \pm 30) \mathrm{nm}$ with a transition zone thickness from the fully densified material to the elastically deformed one ranging between 115 and $165 \mathrm{~nm}$.
\end{abstract}

\section{INTRODUCTION}

Although silica glass has an estimated theoretical strength of 35 $\mathrm{GPa},{ }^{1}$ its extreme sensitivity to surface imperfections or damage is often attributed to the considerably lower strength values reported for bulk samples (of the order of $20 \mathrm{MPa})^{2}$ is often attributed to an extreme sensitivity to surface damage. Such surface imperfections or damage often result from the mechanical contact of the pristine glass surface with hard particles. Such an event may leave behind on the surface a permanent imprint and, providing the applied load is high enough, a well developed cracking system. ${ }^{3}$ As the indentation test best mimics everyday life surface aggression, it makes this technique extremely popular and suitable for studying surface damage properties of materials in general. In using this technique it was shown that oxide glasses deform at first elastically and then in a permanent way through two concomitant deformation mechanisms: a volume conservative one (shear flow) and a nonvolume conservative one (densification). ${ }^{4-6}$ Their relative importance is believed to play a major role in the so-called normal (densification and shear flow such as soda-lime silica glass, WG) or anomalous (mainly densification such as silica glass) behavior exhibited by glasses and may trigger the occurrence of the median/radial crack system, ${ }^{7}$ the most jeopardizing crack system regarding the mechanical integrity of glass structures. Therefore, deformation mechanisms are of first importance to understand the nucleation of crack systems under sharp contact conditions. Indentation imprints are surrounded by a plastically deformed material, ${ }^{5,8}$ the structural properties of which have been permanently modified. From high hydrostatic pressure experiments ${ }^{9,10}$ it was established that for silica glass (WG) permanent densification starts above a threshold value of 10 $\mathrm{GPa}(8 \mathrm{GPa})$ and saturates at a level of $\Delta \rho / \rho_{0}=20 \%(6.3 \%, \rho$ : density) above a pressure level of $25 \mathrm{GPa}(20 \mathrm{GPa}){ }^{11,12}$ In the case of silica glass the permanently densified material does not show any short-range order modifications. ${ }^{13} \mathrm{SiO}_{4}$ tetrahedra remain unaltered, and coordination numbers of $\mathrm{Si}$ and $\mathrm{O}$ atoms return, upon decompression, to their original value, 4 and 2 , respectively. ${ }^{14}$ Nonetheless, the medium range order is significantly modified. The fully densified silica glass (20\%) exhibits a lower intertetrahedral $\mathrm{Si}-\mathrm{O}-\mathrm{Si}$ bond angle value $\left(138.3^{\circ}\right)$. A decrease in the densification effect in denser 
structures is also reported: for 3-fold and 4-fold rings, a variation $\Delta \theta_{\mathrm{Si}-\mathrm{O}-\mathrm{Si}}$ of $-0.56^{\circ}$ and $-1.3^{\circ}$ is reported, respectively, while a $-5.7^{\circ}$ mean value is mentioned for larger structures. An increase of the 3 -fold ring concentration $(\times 3.5)$ is also reported. ${ }^{15,16}$ For WG, a decrease in the $\mathrm{Si}-\mathrm{O}-\mathrm{Si}$ bond angle is reported as well; ${ }^{17-19}$ clustering of modifying ions ${ }^{19}$ was also reported as a possible mechanism of permanent structural modification under high pressure. Recently ${ }^{20}$ it was experimentally shown that permanent densification of a WG glass resulted in an increase in $\mathrm{Q}_{2}$ species at the expense of $\mathrm{Q}_{3}$ species, leading to a lesser connectivity of the densified network. Amazingly permanent densification of silicate glasses may be cured and the initially densified volumes recovered after the following thermal treatment: $0.9 \times T_{\mathrm{g}}$ for $2 \mathrm{~h}\left(T_{\mathrm{g}}\right.$ is the transition temperature of the glass expressed in Kelvin). ${ }^{10}$ The postthermal treatment volume recovery, at indentation sites, was evidenced by atomic force microscopy (AFM) images of the impression prior to and after thermal treatment. ${ }^{29}$ The local densification at indentation sites was successfully observed either through a locally modified refractive index ${ }^{25}$ or by $\mathrm{IR}^{26}$ or by micro-Raman spectroscopy. ${ }^{20,27,28}$ The Raman signature of the densified glass under the residual imprint disappears after a $0.9 \times T_{\mathrm{g}}$ for $2 \mathrm{~h}$ thermal treatment. ${ }^{29}$ Raman spectroscopy was further successfully applied for mapping out densified areas under $20 \mathrm{~N}$ Vickers indentations and its results used as a discriminating sieve to validate constitutive law for glass. ${ }^{27,30}$ Nonetheless, the authors had to use high indentation loads (20 $\mathrm{N})$ to make the densified zone large enough in regard to the spatial resolution of the micro-Raman probe. The authors also reported that full densification of the glass was not reached under $20 \mathrm{~N}$ Vickers indentations (WG and silica glass). Only a fraction of their respective glass saturation level, $80 \%$ (silica) and $60 \%$ (WG), was reached. Nonetheless, 3D Raman cartography on a $500 \mathrm{mN}$ Vickers indentation on silica glass revealed that full densification $(20 \%)$ of the glass was reached. ${ }^{28}$ Such a difference may find an explanation in the presence of a massively fractured zone underneath high load indentations. Fracture is an energy-dissipative process that might impede the attainment of the required level of stress for full densification. In this study we use loads 3 orders of magnitude lower than this (10 and $50 \mathrm{mN}$ ) in order to limit, as much as possible, the effect of the fracture event on deformation mechanisms. Unfortunately, for such small indentation loads no experimental technique exists to characterize the zone affected by densification.

Thus, the aim of this work is, on the one hand, to study the effect of surface defects such as indentations on the chemical durability in a basic solution of two silicate glasses and, on the other hand, from the analysis of presently reported experimental data to propose a way for exploring the volume of material affected by densification after nanoindentation tests. From the temporal evolution of the shape of indentation impressions (characterized by AFM) with dissolution time, the occurrence of an enhanced dissolution rate at indentation sites is reported. We show how this may be linked to the postindentation densified material. Finally, once related to densification, we demonstrate that this enhanced dissolution rate may provide an efficient tool for probing, with a nanometer scale sensitivity, the permanently densified material lying underneath indentation imprints.

\section{EXPERIMENTAL SECTION}

Sample Preparation. Two commercially available glass compositions were used in this study: a floated window glass (WG) (chemical composition: $70.8 \mathrm{SiO}_{2}, 12.8 \mathrm{Na}_{2} \mathrm{O}, 10.2 \mathrm{CaO}$, 5.9 $\mathrm{MgO}, 0.33 \mathrm{Al}_{2} \mathrm{O}_{3}$ $\left.(\mathrm{mol} \%), \rho_{0}=2.55 \mathrm{~g} / \mathrm{cm}^{3}\right)$ and a silica glass $\left(\mathrm{SiO}_{2} 99.6(\mathrm{~mol} \%), \rho_{0}=\right.$ $2.2 \mathrm{~g} / \mathrm{cm}^{3}$ ), both from Saint Gobain Co. The silica glass surface was optically polished and subsequently annealed at $T_{\mathrm{g}}\left(1100{ }^{\circ} \mathrm{C}\right)$ for $2 \mathrm{~h}$ while the air side of WG was tested as received. One extra data set (WG10*) was collected on WG from the air side surface of a thermally annealed sample $\left(T_{\mathrm{g}}=565^{\circ} \mathrm{C}\right.$ for $\left.2 \mathrm{~h}\right)$. $\mathrm{S}_{1}$ samples were kept indentfree for dissolution rate measurements of respective glasses in their relaxed state while the other two $\left(S_{2}\right.$ and $\left.S_{3}\right)$ were indented at 10 and $50 \mathrm{mN}$. Sets of five Vickers indents were made with an indenter instrument (Fischerscope H100CXYp) equipped with a square-based diamond pyramid with an apical angle of $136^{\circ}$ and a line conjunction of roughly $120 \mathrm{~nm}$. Loading and unloading rates were kept constant and equal to $5 \mathrm{mN} / \mathrm{s}$, with a dwell time of $5 \mathrm{~s}$ at maximum load. These loads were chosen so that the residual imprints were free of corner cracks. While $S_{2}$ samples were kept as indented for dissolution testing, $\mathrm{S}_{3}$ samples were thermally treated according to a procedure described in ref 29 to heal structural modifications induced by the indentation process.

Experimental Setup. $S_{1}, S_{2}$, and $S_{3}$ glass samples were placed in separate Teflon containers filled with $50 \mathrm{~mL}$ of a $0.1 \mathrm{~N} \mathrm{NaOH}$ solution $(\mathrm{pH}=13$ at room temperature $)$ and placed in a thermally regulated furnace at $(80.0 \pm 0.5){ }^{\circ} \mathrm{C}$. Although the $\mathrm{S} / \mathrm{v}$ ratio (S: surface of the sample exposed to the solution, v: volume of the solution) was low enough to avoid any saturation of the solutions, they were renewed after $80 \mathrm{~h}$ of effective dissolution time. The weight loss method was used to compute the dissolution rate of the glass $\left(V_{0}\right)$ in its relaxed state $\left(S_{1}\right.$ samples $)$ over a $0-170 \mathrm{~h}$ (7 points) time period. The indented glass samples $S_{2}$ and $S_{3}$, immersed in the heated $(\mathrm{NaOH})$ solution, were periodically taken out and rinsed with deionized water and then ethanol prior to AFM observations. Dissolution times were 3, $16,22,40,83,103$, and $171 \mathrm{~h}$ (total time spent in the solution) for WG and 3, 9, 17, 40, 64, 104, and $176 \mathrm{~h}$ for silica.

Atomic Force Microscopy. The three-dimensional geometry of the imprint was carefully recorded after each dissolution period using the tapping mode of an atomic force microscope (Bruker, Nanoscope V, Santa Barbara, CA) equipped with silicon tips (TAP $300 \mathrm{Al}$ ) of tip radii no larger than $10 \mathrm{~nm}$. Due to both a smaller tip radius and a sharper apical angle when compared to the those of the indenter, the geometry of the imprint is not altered by the atomic force microscope tip. Prior to any series of measurements, the atomic force microscope was calibrated with several grids: a $10 \mu \mathrm{m}$ pitch of $200 \mathrm{~nm}$ deep squared holes and a $3 \mu \mathrm{m}$ pitch of $(23 \pm 1) \mathrm{nm}$ deep engraved features. Moreover, to limit the effect of typical AFM artifacts on our measurements such as thermal drift and piezo creep, thermal equilibrium of the system was established (about $2 \mathrm{~h}$ ) before capturing the first image. The orientation of the sample in the referential of the atomic force microscope was kept constant throughout the whole experiment to allow a direct comparison between images during the dissolution time. The size of the scanned area was large enough so that a sufficient area unaffected by the indentation process exists and may be taken as a reference surface (i.e., set to zero tilt and zero offset). For each condition (glass composition, annealing), a number of five indents were studied as a function of corrosion time. Each data point in Figures 3 and 4 is an average value computed over three to five different indents.

\section{RESULTS AND DISCUSSION}

Evolution of the Imprint Geometry with Dissolution. Before going further into detail, one must understand how the 3D shape of surface features evolve through dissolution. In the case of a homogeneous dissolution rate over the entire surface of the sample (case for a stress-free flat surface), the dissolution vector, at least at a supramolecular level, is applied perpendicularly to the surface. ${ }^{31,32}$ For simplicity, we consider 
indentation imprints to be rather opened defects (surface curvature and mass transportation effects are neglected), and the postindentation residual stress effects on local dissolution rates are neglected. Thus, the magnitude of the dissolution rate is constant all over the surface and in the imprint as well. In other words, in the case of an impression presenting a rounded bottom, as always the case experimentally, both the dissolution vectors at the bottom of the impression and at a horizontal and flat surface located far from the imprint have the same vertical direction and magnitude (Figure 2, $\mathrm{S}_{3}$ sample). Therefore, although the 3D shape of the imprint evolves with dissolution time (concave surfaces tend to expand while convex surfaces tend to disappear), the depth of the imprint, in the scope of our hypotheses, should remain constant. ${ }^{33}$ Any discrepancy in this trend (i.e., an increase or a decrease of the imprint depth) would be the expression of a difference in dissolution rate between the bottom of the imprint and the surface. Recent studies have reported such variations in the etching rate at indentation or scratch sites for borate and aluminosilicate glasses in HF solutions. ${ }^{33-36}$ A decrease in the indented zone etching rate (up to 5 times) was qualitatively associated with the phenomenon of densification, which was used as a shield for engraving convex features onto the glass surface. Nonetheless, no etching rate variation was reported for a glass similar to WG. ${ }^{33}$ This was interpreted as an absence of dissolution rate modification of the densified material. These statements may look somewhat opposite to the experimental observations reported later in this manuscript. Nonetheless, the etching mechanism in HF solutions ${ }^{37-39}$ and the dissolution mechanism in basic solutions (present study) ${ }^{40}$ are quite different. Regarding the evolution of the shape of indentation imprints with dissolution time, one observation is worth mentioning as a general behavior. For both $S_{2}$ and $S_{3}$ samples, the originally inverted squared pyramidal shape of the residual imprint progressively evolves toward a hemispherical-like shape with dissolution time (Figures 1 and 2). The intersection of the impression with the free surface becomes eventually a perfect circle for long dissolution times (Figure 1). Although theoretically possible, the extraction of $3 \mathrm{D}$ information on

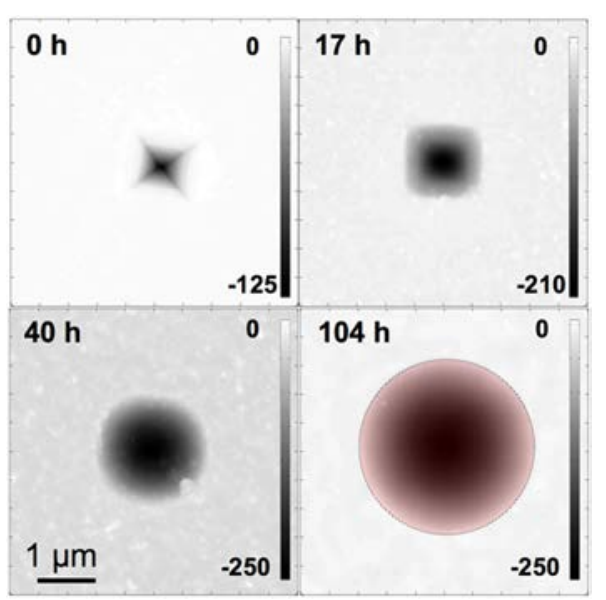

Figure 1. AFM images $\left(5 \times 5 \mu \mathrm{m}^{2}\right)$ presenting the evolution of a Vickers indentation $(10 \mathrm{mN}$, silica) with dissolution time: $0 \mathrm{~h}, 17 \mathrm{~h}, 40$ $\mathrm{h}, 104 \mathrm{~h}$. Respective $Z$ scales are reported in nanometers on the extreme right of each picture. The dotted line describing a circle (104 h) illustrates the perfect circular shape of the impression for long dissolution periods.

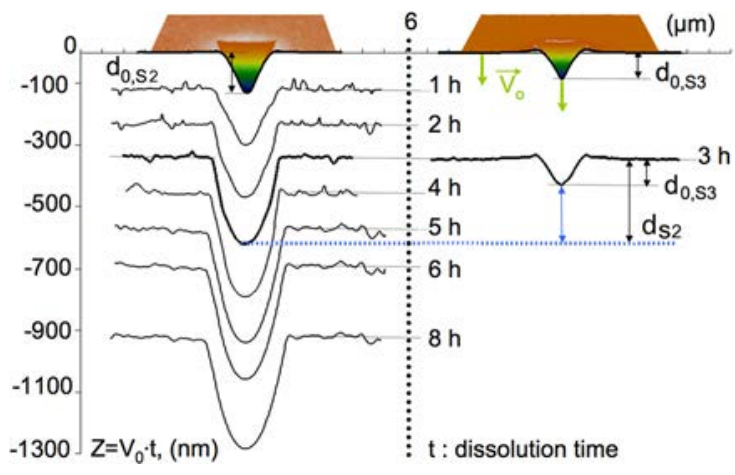

Figure 2. Evolution (profiles perpendicular to the face) of a $10 \mathrm{mN}$ Vickers indentation on WG as a function of dissolution time in a $0.1 \mathrm{~N}$ $\mathrm{NaOH}$ solution: (a) as indented (WG10*, $\mathrm{S}_{2}$ sample); (b) after a 0.9 $\times T_{\mathrm{g}}(\mathrm{K}), 2 \mathrm{~h}$ thermal treatment $\left(\mathrm{S}_{3}\right.$ sample). $Z=0 \mathrm{~nm}$ is the initial surface of the sample before dissolution $(t=0 \mathrm{~h}) . Z=V_{0}$. $t$ is the thickness of glass dissolved away during the time $t$. This figure was prepared with GIMP ${ }^{41}$ and Gwyddion ${ }^{42}$ softwares.

dissolution rates around the indentation requires specific $3 \mathrm{D}$ image treatments, which are currently under development. Nonetheless, 3D information is not necessary for the present work. In the remainder of the manuscript we will focus on $1 \mathrm{D}$ information, that is to say the evolution of the depth of postindentation impressions (Figures 3 and 4) versus

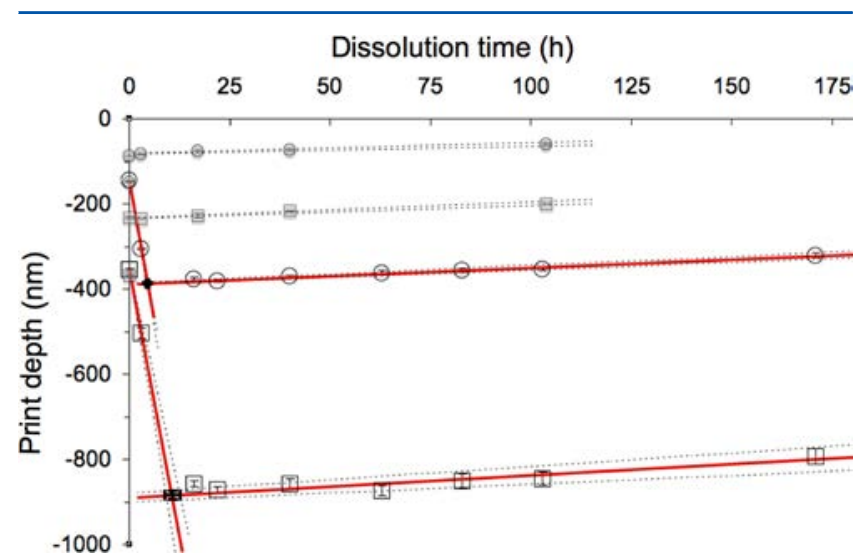

Figure 3. Impression depth evolution of $50 \mathrm{mN}$ (squares) and $10 \mathrm{mN}$ (circles) load Vickers indentations made on WG glass surface (air side, as received) versus dissolution time in a $0.1 \mathrm{~N} \mathrm{NaOH}$ solution at 80 ${ }^{\circ} \mathrm{C}$. Opened symbols are for unannealed indentations ( $\mathrm{S}_{2}$ samples). Gray symbols stand for thermally annealed indentations at $0.9 \times T_{\mathrm{g}}$ during $2 \mathrm{~h}\left(\mathrm{~S}_{3}\right.$ samples). Vertical error bars represent \pm 1 standard deviation; if not visible, the error bar is smaller than the size of the reported symbol.

dissolution time. For $S_{1}$ samples, dissolution rates of the relaxed glass $\left(V_{0}\right.$, of $(66.1 \pm 1.1) \mathrm{nm} / \mathrm{h}(R=0.9992)$ and $(115.1 \pm 0.6) \mathrm{nm} / \mathrm{h}(R=0.9999))$ were measured over a $170 \mathrm{~h}$ period for silica and WG glasses, respectively.

Temporal Evolution of Indentation Impression Depth: $\mathrm{S}_{2}$ Samples. Regardless of both the glass composition and the indentation load, the variation in the impression depth versus dissolution time exhibits two different regimes (Figures 3 and 4): a first one (region I), at short dissolution times, for which the impression depth increases sharply with dissolution time, and a second one (region II), for long dissolution times, for which the imprint depth stays quasiconstant. In the case of WG samples, for both $10 \mathrm{mN}$ and $50 \mathrm{mN}$ indentation loads, region I 


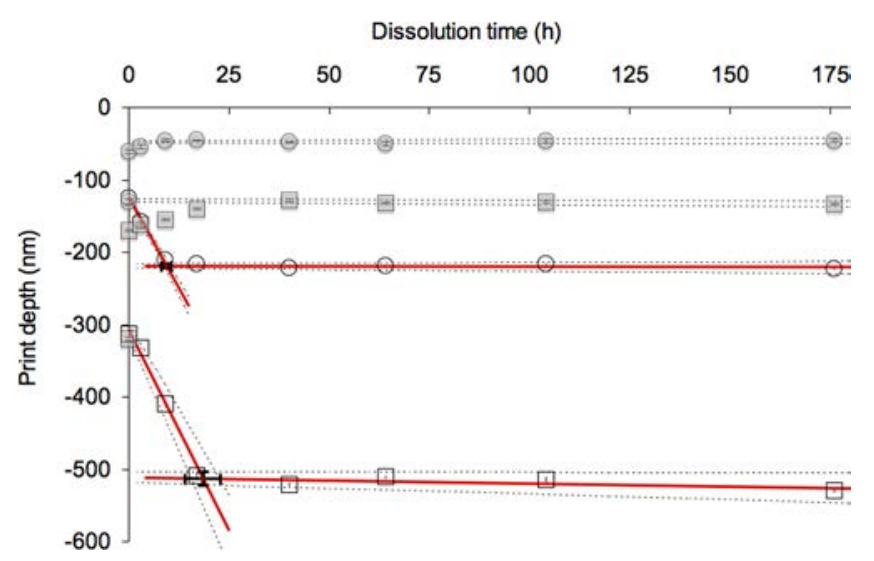

Figure 4. Impression depth evolution of $50 \mathrm{mN}$ (squares) and $10 \mathrm{mN}$ (circles) load Vickers indentations made on silica glass versus dissolution time in a $0.1 \mathrm{~N} \mathrm{NaOH}$ solution at $80{ }^{\circ} \mathrm{C}$. Open symbols are for unannealed indentations $\left(S_{2}\right.$ sample), and grayed symbols stand for thermally annealed indentations at $0.9 \times T_{\mathrm{g}}$ during $2 \mathrm{~h}\left(\mathrm{~S}_{3}\right.$ sample).Vertical error bars represent \pm 1 standard deviation; if not visible, the error bar is smaller than the size of the reported symbol.

suffers greatly from a lack of data points. Further experiments were recently carried out on $10 \mathrm{mN}$ indentations (Figure 5), and the results confirm the linear trends of both regions I and II which are also observed for silica glass (Figure 4). Therefore, both regions were fitted using a linear regression analysis method (Figures 3 and 4), and results are listed in Table 1. For both regions I and II, the different slope values $\left(\Delta \mathrm{V}_{\mathrm{I}}\right.$ and $\left.\Delta \mathrm{V}_{\mathrm{II}}\right)$ computed for a given glass composition are extremely similar and look rather load independent. Although both glass compositions present a qualitatively identical behavior, quantitative data such as $\Delta V_{\mathrm{I}}(-51.6 \mathrm{~nm} / \mathrm{h}$ and $-10.5 \mathrm{~nm} / \mathrm{h}$ for WG and silica, respectively) and $\Delta V_{\text {II }}$ (roughly $0.41 \mathrm{~nm} / \mathrm{h}$ and $0 \mathrm{~nm} / \mathrm{h}$ for $\mathrm{WG}$ and silica, respectively) are glass composition dependent. The intersection between regions I and II is of interest, as it roughly represents both the time $\left(t^{*}\right)$ at which the depth of the impression does not increase anymore and the maximum depth $\left(d^{*}\right)$ reached by the impression (Table 2). $t^{*}$ is both load and composition dependent, and its value rises with indentation load. The increase in the imprint depth with dissolution time reflects the existence of a faster and time-limited dissolution rate at the bottom of the impression. As dissolution time passes, the glass surface dissolves away. We are in fact probing the material in depth at a rate $V_{0}$. Thus, the time-limited enhanced dissolution rate means that only a limited thickness of glass underneath the residual impression exhibits a faster dissolution rate.

Temporal Evolution of Indentation Impression Depth for $\mathrm{S}_{3}$ Samples. For WG glass, only region II is observed. Almost no increase in the impression depth (Figures 2 and 3) is observed whereas for silica glass the impression depth starts to decrease slightly before reaching a horizontal plateau (region II). For the latter, region I is characterized by a positive slope $\Delta V_{\mathrm{I}}$ of $(1.6 \pm 0.2) \mathrm{nm} / \mathrm{h}$ and $(1.7 \pm 0.1) \mathrm{nm} / \mathrm{h}$ for the $10 \mathrm{mN}$ and the $50 \mathrm{mN}$ load, respectively. The possible origin of this positive slope will be discussed later in the manuscript (see section discussing the possible effect of residual stress on dissolution rate). $\Delta V_{\text {II }}$ values look rather load independent and are similar to the ones computed for $S_{2}$ samples (see Table 1). Region II may be characterized by a mean slope equal to $(-0.03 \pm 0.04) \mathrm{nm} / \mathrm{h}$ for silica and $(0.36 \pm 0.11) \mathrm{nm} / \mathrm{h}$ for $\mathrm{WG}$ for times as long as $176 \mathrm{~h}$. Such differences in dissolution rate may come either from (a) surface curvature, (b) change of material composition, (c) residual stress, or (d) mass transport of the reaction product from the reaction site to the bulk of the solution. As impressions on both silica and WG glasses have similar shapes, where curvature varies with dissolution time, and because the slope of region II stays constant over long dissolution times, points $\mathrm{a}-\mathrm{c}$ may be ruled out. Although more specific work should be performed to clarify this, differences in $\Delta V_{\text {II }}$ values might probably find its origin in point $\mathrm{d}$ and in the chemical composition of the two glasses. Still, it shows this technique to be extremely sensitive to small differences in dissolution rates, of a few $\mathrm{Si}-\mathrm{O}$ atomic bonds per hour.

On the Enhanced Dissolution Rate and the Permanent Densification of Glass. Dissolution mechanism (hydrolysis of $\mathrm{Si}-\mathrm{O}$ bonds) of silicate glasses in basic aqueous solutions occurs through the following overall reaction: ${ }^{43} \mathrm{Si}-$ $\mathrm{O}-\mathrm{Si}+\mathrm{OH}^{-} \leftrightarrow \mathrm{SiO}^{-} \cdot$ HOSi. Doremus ${ }^{40}$ stated that dissolution rates are intimately linked to the openness of the glass surface; nonetheless, high $\mathrm{pH}$ values (above 9) level this
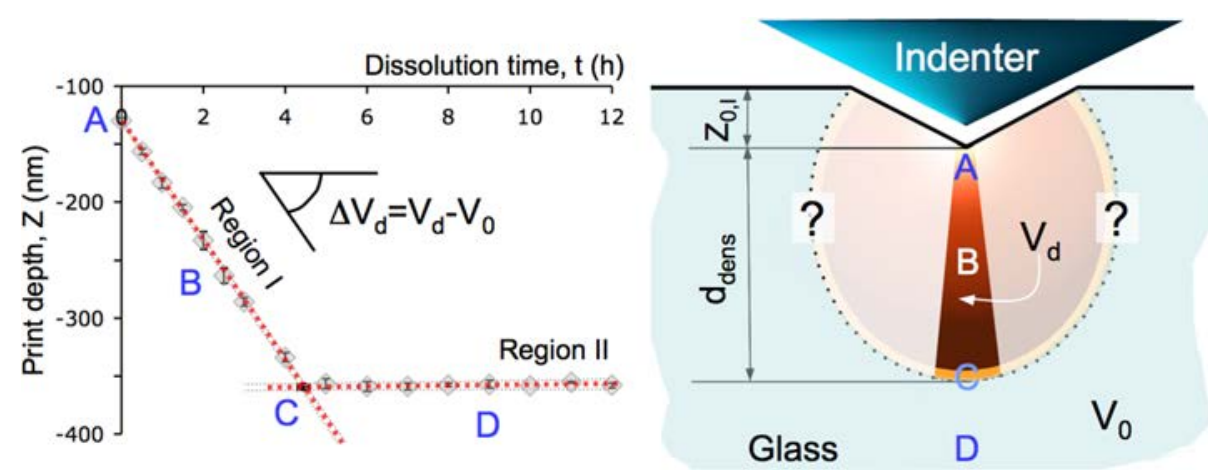

Figure 5. Left: evolution of a $10 \mathrm{mN}$ Vickers indentation impression depth made on a WG annealed glass surface with dissolution time (WG10*). Right: schematic representation of the permanently densified glass zone under a residual indent. For both images: Point $\mathrm{A}$ (left) is the depth $\left(Z_{0, \mathrm{I}}\right)$ of the imprint after indentation; point A (right) is the bottom of the imprint after indentation. Point B (left) belongs to region I for which the bottom of the imprint dissolves away faster, at a constant rate $V_{\mathrm{d}}$, than the relaxed glass surface; point $\mathrm{B}$ (right) indicates the region under the imprint where $V_{\mathrm{d}}=V_{0}+\Delta V_{\mathrm{d}}$ is experimentally measured. Point C (left) refers to the transition between regions I and II; point $\mathrm{C}$ (right) designates the transition zone where the densified state goes from fully densified to undensified. Point $\mathrm{D}$ (left) indicates the plateau region named region II for which $V_{\mathrm{d}}-V_{0}$ $\approx 0$; point $\mathrm{D}$ (right) refers to the region where the dissolution rate is equal to $V_{0}$. Information in the shaded areas could not be investigated in the present study. 
Table 1. Linear Regression Analysis Parameters for $S_{2}$ Samples (with WG10*) and $S_{3}$ Samples for WG and Silica Glasses ${ }^{a}$

\begin{tabular}{|c|c|c|c|c|c|c|c|c|c|c|}
\hline & & \multicolumn{5}{|c|}{$\mathrm{S}_{2}$ samples } & \multicolumn{4}{|c|}{$\mathrm{S}_{3}$ samples } \\
\hline & & \multicolumn{3}{|c|}{ WG glass } & \multicolumn{2}{|c|}{ silica } & \multicolumn{2}{|c|}{ WG glass } & \multicolumn{2}{|c|}{ silica } \\
\hline & & $10 \mathrm{mN}$ & $50 \mathrm{mN}$ & $10^{*} \mathrm{mN}$ & $10 \mathrm{mN}$ & $50 \mathrm{mN}$ & $10 \mathrm{mN}$ & $50 \mathrm{mN}$ & $10 \mathrm{mN}$ & $50 \mathrm{mN}$ \\
\hline \multirow[t]{4}{*}{ region I } & $\begin{array}{l}\Delta V_{\mathrm{I}} \\
(\mathrm{nm} / \mathrm{h})\end{array}$ & $-53.6(2)$ & $-49.8(2)$ & $-51.4(8)$ & $-10.1(3)$ & $-11.1(3)$ & NA & NA & $1.6(3)$ & $1.7(4)$ \\
\hline & $\sigma\left(\Delta V_{\mathrm{I}}\right)$ & 2.1 & 7.6 & 0.7 & 0.6 & 1.6 & NA & NA & 0.2 & 0.1 \\
\hline & $Z_{0, \mathrm{I}}(\mathrm{nm})$ & -145.4 & -354.6 & -130.7 & -127.8 & -307.7 & NA & NA & -60.2 & -169.2 \\
\hline & $\sigma\left(\mathrm{Z}_{0, \mathrm{I}}\right)$ & 2.4 & 4.9 & 1.5 & 3.1 & 9.0 & NA & NA & 1.2 & 1.2 \\
\hline \multirow[t]{4}{*}{ region II } & $\begin{array}{l}\Delta V_{\mathrm{II}} \\
(\mathrm{nm} / \mathrm{h})\end{array}$ & $0.38(7)$ & $0.52(6)$ & $0.35(7)$ & $-0.01(4)$ & -0.09 & $0.21(5)$ & $0.34(5)$ & $0.004(6)$ & $-0.03(4)$ \\
\hline & $\sigma\left(\Delta V_{\mathrm{II}}\right)$ & 0.03 & 0.11 & 0.21 & 0.03 & 0.07 & 0.03 & 0.03 & 0.015 & 0.02 \\
\hline & $Z_{0, \mathrm{II}}(\mathrm{nm})$ & -387.7 & -889.7 & -361 & -218.9 & -510.6 & -82.4 & -233.7 & -47.2 & -128.5 \\
\hline & $\sigma\left(Z_{0, \mathrm{II}}\right)$ & 2.6 & 10.1 & 1.9 & 3.1 & 7.8 & 1.6 & 1.8 & 1.4 & 1.8 \\
\hline
\end{tabular}

${ }^{a}$ Numbers inside brackets stand for the number of points taken into account for the computation. $10^{*}$ stands for WG10*. $Z_{0,1}$ : initial impression depth; $\Delta V_{\mathrm{I}(\mathrm{II})}$ : slope of region I (II). $\sigma()$ stands for one standard deviation. NA: nonapplicable.

Table 2. Points of Intersection $\left(t^{*}, d^{*}\right)$ between Regions I and II (samples $S_{2}$ ) Computed from Table $1^{a}$

\begin{tabular}{ccccccc} 
& \multicolumn{3}{c}{ WG glass } & & \multicolumn{2}{c}{ silica } \\
\cline { 2 - 3 } \cline { 6 - 7 } \cline { 5 - 7 }$t^{*}(\mathrm{~h})$ & $10 \mathrm{mN}$ & $50 \mathrm{mN}$ & $10^{*} \mathrm{mN}$ & & $10 \mathrm{mN}$ & $50 \mathrm{mN}$ \\
$\sigma\left(t^{*}\right)$ & 4.5 & 10.6 & 4.5 & & 9.4 & 18.4 \\
$d^{*}(\mathrm{~nm})$ & -386 & -884 & -359 & & -219 & -513 \\
$\sigma\left(d^{*}\right)$ & 3 & 11 & 3 & & 3 & 9 \\
$d_{\text {dens }}(\mathrm{nm})$ & -748 & -1808 & -741 & & -726 & -1442 \\
$\sigma\left(d_{\text {dens }}\right)$ & 40 & 341 & 37 & & 57 & 259
\end{tabular}

${ }^{a}$ Densification depth $\left(d_{\text {dens }}\right)$ or depth below the impression apex $\left(Z_{0, \mathrm{I}}\right)$ at which regions I and II intersect. Plan of origin $(z=0)$ is at $t=0$ (Figure 2). 10* stands for WG10*.

effect and significantly increase the reaction rate which results from a sharp increase in the solubility of silicate species in the solution. It is also well-known that glass network deformation due to a high level of stress can modify the onset and the rate of the reaction of hydrolysis, as for example at the tip of a crack where it is responsible for the subcritical crack growth phenomenon observed in oxide glasses. ${ }^{23,24}$ Among all possible structural deformations of the silica network under stress, the $\mathrm{Si}-\mathrm{O}-\mathrm{Si}$ bond angle plays a major role. Michalske and Bunker $^{24}$ reported that a decrease in the siloxane bond angle could result in a decrease in the resistance to hydrolysis of the $\mathrm{Si}-\mathrm{O}$ bond to $25 \%$ of its original value. Other numerical studies have since confirmed the important effect of silica network deformation on the chemical reactivity of the $\mathrm{Si}-\mathrm{O}$ bonds with water molecules. ${ }^{21,22}$

Regarding densification and associated structural modifications, two recent studies have dealt with glass having the same chemical composition as the glasses presently studied. ${ }^{15,20}$ For silica glass, a progressive decrease in the mean $\mathrm{Si}-\mathrm{O}-\mathrm{Si}$ bond angle value with the increasing level of permanent densification is reported. Hehlen also stated that those structural changes may depend on the densification process as, for example, the effect of temperature or the presence of a shear stress component. Nonetheless, regarding this latter point, it was recently shown, for WG glass, ${ }^{20}$ that shear does not affect the nature of the structural modifications in the permanently densified glass. For WG, a decrease in the $\mathrm{Si}-\mathrm{O}-\mathrm{Si}$ mean bond angle value occurs as well but a connectivity loss of the densified glassy network is also reported. All the aforementioned structural changes may lead to an increase in the overall dissolution rate of the glass, whether it is due to a $\mathrm{Si}-\mathrm{O}-\mathrm{Si}$ mean bond angle decrease or/and to a loss of connectivity (i.e., lesser $\mathrm{Si}-\mathrm{O}$ bonds to hydrolyze per unit volume). This latter point provides first evidence that the enhanced dissolution rate reported in the present study could result from the presence of permanently densified glass under residual indentation imprints.

Other results from the scientific literature may be gathered and efficiently used for establishing a link between permanent densification underneath indentations and a locally enhanced dissolution rate. For instance, contact mechanic associated with three-dimensional finite element analysis simulation. ${ }^{12,27,49}$ It was shown that a finite volume under the indentation imprint is affected by densification. Depending on the constitutive law used for computation, the saturation level is either reached in an extended zone with a steep gradient between the fully densified and the nonpermanently densified material ${ }^{49}$ (as illustrated in Figure 5) or in a rather limited zone close to the indent with a progressive and large transition zone as one moves away from the indent. ${ }^{27}$ The latter scenario was experimentally observed using micro-Raman cartography of high load indentations $(20 \mathrm{~N})$ on silica glass and WG. ${ }^{20,27}$ This size-limited zone of permanently densified material is also in agreement with our experimental observations where both glasses present an enhanced dissolution rate for a limited dissolution time (i.e., limited depth under the imprint). The last but certainly the strongest argument is undoubtedly the vanishing of the faster dissolution rate measured at indentation sites after thermal treatment $\left(S_{3}\right.$ samples) which can be straightforwardly related to the disappearance of the Raman signature of the densified glass under an indent after the same thermal treatment. ${ }^{29}$ All together those arguments give strong evidence for this depth-limited enhanced dissolution rate observed experimentally at indentation sites to be a direct consequence of the presence of permanently densified glass underneath residual indentation impression.

Nonetheless, one point has to be considered. It is rather surprising that the glass showing the highest densification ratio (volumetric strain), 20\% (-16.7\%) and 6.3\% (-5.9\%) for silica and WG glass, respectively, which as a first approximation may be interpreted as the most deformed glassy network, is the one presenting the smallest relative dissolution rate enhancement $-\Delta V_{\mathrm{I}} / V_{0}$ ( $16 \%$ and $45 \%$ for silica glass and WG glass, respectively). It is naturally tempting to associate a lower mean reactivity to $\mathrm{WG}$, the lesser deformed silicate network (i.e., a 
lower $\mathrm{Si}-\mathrm{O}-\mathrm{Si}$ variation). Unfortunately $-\Delta V_{\mathrm{I}} / V_{0}$ numbers cannot be used for direct comparison between glass compositions. Indeed, one must think in terms of the number of $\mathrm{Si}-\mathrm{O}$ bonds being hydrolyzed per unit surface per time lap to make possible such a comparison. We call it $\mathrm{Si}-\mathrm{O}$ bond hydrolysis rate $\left(V_{\mathrm{Si}-0}\right)$. Furthermore the densification effect on $\rho$ values has to be taken into account. ${ }^{48}$ For computing $V_{\mathrm{Si}-0}$, we need to address some structural considerations. The silica network is a rather complicated 3D structure that is built from $\mathrm{SiO}_{4 / 2}$ tetrahedra in which the coordination number of $\mathrm{Si}$ and $\mathrm{O}$ atoms is 4 and 2, respectively. Neither the coordination number of Si nor the geometry of the tetrahedra is significantly modified in the permanently densified glass. ${ }^{44,45}$ The structure of a glass can also be discussed in terms of mean connectivity, which is best described by the statistical repartition of $\mathrm{Q}_{n}$ species $(n=1$ to 4$) .{ }^{46}$ We assume here for simplicity that silica glass is only made of $\mathrm{Q}_{4}$ species. At a longer range order, although tetrahedra can connect to each other by their edges, they mostly form the silica network by corner sharing, forming a network of $m$-fold three-dimensional rings. $m$, the number of tetrahedra per ring, ranges from 2 to 9 with a statistical distribution peaking at $m=5$ or $6 .{ }^{47}$ Connection between tetrahedra is best described by the intertetrahedral angle $\mathrm{Si}-$ $\mathrm{O}-\mathrm{Si}$ which presents a broad distribution centered on a mean value of the order of $144^{\circ}$. In the case of WG glass the introduction of network modifiers such as $\mathrm{Na}^{+}, \mathrm{Mg}^{2+}$, or $\mathrm{Ca}^{2+}$ will increase the amount of $\mathrm{Q}_{n}(n<4)$ species, resulting in a decrease in the silica network connectivity. Thus, to calculate $V_{\mathrm{Si}-0}$ we have to make the assumption that the dissolution rate is essentially limited by the kinetic of the $\mathrm{Si}-\mathrm{O}$ bond hydrolysis. This is true at high $\mathrm{pH}$ value and far from saturation. Therefore, knowing the volumetric density of $\mathrm{Si}-\mathrm{O}$ bonds from the chemical composition and $\rho$, dissolution rates $(\mathrm{nm} / \mathrm{h})$ can be readily transformed into $\mathrm{Si}-\mathrm{O}$ hydrolysis rates. Meanwhile, in the case of WG glass we take into account the global connectivity loss of the network by assuming that each $\mathrm{R}^{+}$and each $\mathrm{R}^{2+}$ ion creates a $\mathrm{Q}_{3}$ and a $\mathrm{Q}_{2}$ species, respectively. For the relaxed state $\left(\mathrm{S}_{1}\right.$ samples), it becomes $1943 \mathrm{Si}-\mathrm{O} /$ $\mathrm{nm}^{2} / \mathrm{h}$ and $2094 \mathrm{Si}-\mathrm{O} / \mathrm{nm}^{2} / \mathrm{h}$, and for the densified state $\left(\mathrm{S}_{2}\right.$ samples, $\left.V_{\mathrm{d}}=V_{0}-\Delta V_{\mathrm{I}}\right)$, we have $2724 \mathrm{Si}-\mathrm{O} / \mathrm{nm}^{2} / \mathrm{h}$ and 3223 $\mathrm{Si}-\mathrm{O} / \mathrm{nm}^{2} / \mathrm{h}$ for silica glass and WG glass, respectively. This is still a $40 \%$ and $54 \%$ relative increase in $\mathrm{Si}-\mathrm{O}$ hydrolysis rate. Although closer, those values are still not aiming toward the expected trend. Thus, the geometrical deformation of the silica network cannot explain by itself the higher dissolution rate of WG glass. A complementary mechanism (i.e., connectivity loss) leading to an overall increase in the dissolution rate of the permanently densified glass must come into play as recently evidenced by Champagnon. ${ }^{20}$ Unfortunately, it is not possible yet to quantitatively decipher the contribution of $\mathrm{Si}-\mathrm{O}-\mathrm{Si}$ bond angle modification from that of the connectivity loss (volumetric density of $\mathrm{Q}_{2}$ species created) to the dissolution rate. Note that this network connectivity loss also offers an interesting trail to tentatively explain the decrease in hardness $(-8 \%)$ observed for a fully densified soda-lime-silica glass similar to WG whereas the hardness of fully densified silica glass increases by $37 \%{ }^{48}$

Differential Dissolution Rate Measured by AFM as a Nanoprobe for Contact-Induced Densification. As long as the bottom of the impression imaged by the atomic force microscope remains in the densified area it dissolves faster than the relaxed surface (region I, B in Figure 5) resulting in an increase of the imprint depth with dissolution time. The rate of this increase is equal to $-\Delta V_{\mathrm{I}}=V_{\mathrm{d}}-V_{0} \gg 0$, the difference between the dissolution rate of the glassy material present at the bottom of the indentation imprint and the dissolution rate of the relaxed glass. When the bottom reaches the nonpermanently densified area (region II, C) the dissolution rate drops to $V_{0}\left(\Delta \mathrm{V}_{\mathrm{II}} \approx 0\right)$ and no further increase of the impression depth is observed (D). Therefore, the limit of the permanently densified area under the indentation may be defined as the dissolution time needed for reaching region II. From Figure 5 this limit is roughly the depth $\left(d_{\text {dens }}\right)$ and time $\left(t^{*}\right)$ at which region I and region II intersect (point C) (Table 2). $d_{\text {dens }}$ may be easily computed from $t^{*}, V_{0}$, and $\Delta V_{\mathrm{I}}$ by the following relation: $d_{\text {dens }}=\left(V_{0}-\Delta V_{\mathrm{I}}\right) t^{*}$. Results are reported in Table 2. The two $10 \mathrm{mN}$ sets, although carried on two different surface states, give an extremely similar result, $(-748 \pm 51) \mathrm{nm}$ and $(-741 \pm 30) \mathrm{nm}$, respectively, for the unannealed surface and the thermally relaxed one. For the same load, silica presents a lower but quite similar value of $(-726 \pm 57) \mathrm{nm}$ whereas for the $50 \mathrm{mN}$ load, the difference between the two glass compositions is more pronounced $(-1442 \pm 259) \mathrm{nm}$ for silica against $(-1808 \pm 341) \mathrm{nm}$ for WG.

Unfortunately, we do not know how the dissolution rate of the permanently densified glass varies with the level of permanent densification. Nonetheless, as the permanent densification level of the glass increases continuously and progressively with the applied hydrostatic pressure (sigmoidal function), ${ }^{11,20}$ those structural changes are also expected to continuously increase either in numbers of sites per unit volume $\left(\mathrm{Q}_{3} \rightarrow \mathrm{Q}_{2}\right.$ and $\left.\mathrm{Si}-\mathrm{O}-\mathrm{Si}\right)$ and/or in intensity ( $\mathrm{Si}-\mathrm{O}-$ $\mathrm{Si}$ ). Although specific experiments should be carried for establishing a quantitative relationship between the dissolution rate and the densification level of the glass, the variation of dissolution rate with the level of permanent densification should exhibit a roughly qualitatively similar trend, that is to say, a progressive and continuous increase from $V_{0}$, the undensified state, to $V_{\max }$ the fully densified state. Therefore, the constant dissolution rate $V_{\mathrm{d}}$ (i.e., $\Delta V_{\mathrm{I}}=$ constant, region I) experimentally observed, for both glass compositions, over quite a large dissolution time span (i.e., depth under the indent) implies that the entire zone (region I) possesses the same structural state and thus the same level of densification. This is possible over such a depth only if this level of densification is the saturated one $\left(V_{\mathrm{d}}=V_{\max }\right)$.

A transition zone between the fully densified material $\left(V_{\max }\right)$ and the nonpermanently densified material $\left(\approx V_{0}\right)$ has to exist. The WG10* data set offers the possibility to estimate the maximum possible thickness of this transition zone under the indent apex. It is roughly equal to the dissolved thickness between the last and the first points belonging to region I and region II, respectively. This transition zone occurs within a time lag of $1 \mathrm{~h}$ of dissolution (Figure 5), which gives it a thickness between $115 \mathrm{~nm}\left(V_{0}\right)$ and $165 \mathrm{~nm}\left(V_{\mathrm{d}}\right)$.

Further fine experiments are currently being carried out on both WG and silica glass to study the effect of the indentation load on both the transition zone and the size of the area affected by densification.

Possible Effect of Postindentation Residual Stress on Dissolution Rate. The effect of mechanical stress on chemical reaction rates has been widely covered in the literature; see for example refs 50 and 51 and references therein. Briefly, from the thermodynamic viewpoint, it was shown that a compressive stress state increases the free energy of the system (solid/ liquid) thus impeding the reaction of dissolution and vice versa. 
As discussed earlier in this manuscript, the dissolution of oxide glasses in an aqueous environment occurs mainly through the hydrolysis of $\mathrm{Si}-\mathrm{O}-\mathrm{Si}$ bridges which was shown to drastically depend on stress. ${ }^{23,52}$ Moreover Nychka et al., ${ }^{53}$ while studying the bioactiviy of phosphate glasses, attributed the local decrease in dissolution rates around $20 \mathrm{~N}$ indentations to the presence of postindentation compressive residual stress. Surface stress levels of $-1.5 \mathrm{GPa}$ (compression) and 0.35 GPa (tension) were reported around a $45 \mathrm{~N}$ Vickers indentation made on a similar WG glass. ${ }^{54}$ To our knowledge, no quantitative relation exists between the level and state of biaxial stress at a glass surface and its associated dissolution rate in a basic solution. Nonetheless, qualitatively, if a compressive stress state is encountered by the bottom of the indentation, a decrease in the dissolution rate is expected, providing that the stress level is high enough to modify the reaction rate. Note that our reference surface is taken sufficiently far from the indent not to be affected by the postindentation residual stress field. Whereas a residual stress effect could be detected neither for WG $S_{2}$ and $S_{3}$ samples nor for silica $S_{2}$ samples, silica $S_{3}$ samples exhibit a time-limited decrease in the impression depth at a $(1.65 \pm 0.05) \mathrm{nm} / \mathrm{h}$ mean rate (Figure 4). The latter is synonymous to the presence of an in-plane compressive stress state at the bottom of the impression. To help understand the origin of such a difference in behavior between these two glasses, the following two points should be considered:

(1) The $0.9 \times T_{\mathrm{g}}(\mathrm{K})$ for $2 \mathrm{~h}$ thermal treatment only allows a small amount of postindentation residual stress relaxation (around a few \% depending on the considered relaxation model). Thus, the residual stress field in $S_{3}$ samples is only substantially modified by the volume recovery of the densified material present underneath the indent.

(2) The intensity of the volume recovery $\left(-\varepsilon_{\mathrm{v}}\right)$ which occurs after thermal treatment is essentially glass composition dependent: larger for silica $(-16.7 \%)$ than for WG $(-5.9 \%)$.

Our problem can be schematically described in terms of a spherical inclusion of densified material partially embedded in the relaxed glassy material and truncated by the free surface of the imprint (Figure 5). An isotropic volume recovery of the densified material will push the free surface of the imprint up, as observed experimentally. While doing so, the sides of the imprint will be constrained by the surrounding material, introducing an additional compressive stress component at its bottom. For similar elastic properties and densified zone size and shape, the intensity of this additional stress component will depend essentially on the volumetric deformation recovered $\left(\varepsilon_{\mathrm{v}}\right)$. The larger the latter, the higher the contribution. Although more work will be needed to bring a definitive answer to this problem, a qualitative and reasonable explanation is provided for the behavior of silica $\mathrm{S}_{3}$ samples. On the one hand, in the case of silica glass, to notice an effect on the dissolution rate (about $10 \%$ of $\Delta V_{\mathrm{I}}$ ), the contribution of the densified volume recovery to the postindentation stress field is needed and, on the other hand, for WG glass, even with both contributions, no effect could be observed. As a lower compressive stress level is present at the bottom of $S_{2}$ samples indentations, we may conclude that the effect of the residual postindentation stress field on measured $\Delta V$ may be neglected, especially in the case of WG glass. However, in this study we only probe one direction.

\section{CONCLUSION}

The effect of nanoindentations on the chemical durability of silica glass and soda-lime silicate glass (WG) in a basic solution was studied by atomic force microscopy. An enhanced dissolution rate is observed locally at indentation sites and quantified $(+52 \mathrm{~nm} / \mathrm{h}$ and $+10.5 \mathrm{~nm} / \mathrm{h}$ for WG and silica glass, respectively) when compared to that of the relaxed glass.

(1) An enhanced dissolution rate results from local structural changes that occur upon permanent densification. Those structural changes (connectivity loss, $\mathrm{Si}-\mathrm{O}-\mathrm{Si}$ decrease) are in agreement with an increase in the dissolution rate of the permanently densified glass.

(2) The disappearance of the enhanced dissolution rate after a thermal treatment shows the complete reversibility of the local structural changes that occur upon permanent densification.

(3) We show that the enhanced dissolution rate may be used to probe, at the nanometer scale, the densified glass under nanoindentation imprints. The depth affected by densification under $10 \mathrm{mN}$ and $50 \mathrm{mN}$ Vickers indentations is measured.

(4) Our technique has proven to be qualitatively sensitive to fine structural changes, providing that they have an effect on the global dissolution rate.

(5) From our observations, we discuss the possibility of full densification of the glass to be reached under the impression during indentation. The transition zone thickness is computed for a $10 \mathrm{mN}$ load on WG and is no greater than $165 \mathrm{~nm}$.

(6) The possible effect of postindentation residual stress on our measurement is also discussed and found to be negligible in our case.

\section{AUTHOR INFORMATION}

\section{Corresponding Author}

*E-mail: jean-pierre.guin@univ-rennes1.fr.

\section{Present Addresses}

${ }^{\ddagger}$ SIAE Civil Aviation, University of China, Tianjin, China. ${ }^{\S}$ CNRS, INSIS.

\section{Notes}

The authors declare no competing financial interest.

\section{ACKNOWLEDGMENTS}

The regions Pays de la Loire and Bretagne are acknowledged for the Ph.D. grant for Dr. Yi Fan Niu. The French Ministry of Research is acknowledged for the Ph.D. grant for M. K. Han as well as the ANR Grant Program for Young Researchers under the funding reference ANR-07-JCJC-0037 QUIC-Glass.

\section{REFERENCES}

(1) Orowan, E. Fracture and strength of solids. Rep. Prog. Phys. 1949, $12,185-232$.

(2) Griffith, A. A. The phenomena of rupture and flow in solids. Philos. Trans. R. Soc. London 1920, A221, 163-198.

(3) Cook, R.; Pharr, G. Direct observation and analysis of indentation cracking in glasses and ceramics. J. Am. Ceram. Soc. 1990, 73, 787817.

(4) Taylor, E. W. Plastic deformation of optical glass. Nature 1949, $163,323$.

(5) Marsh, D. M. Plastic flow in glass. Proc. R. Soc. London 1964, A279, 420-435. 
(6) Peter, K. Densification and flow phenomena of glass in indentation experiments. J. Non-Cryst. Solids 1970, 5, 103-115.

(7) Lawn, B. R.; Swain, M. V. Microfracture beneath point indentations in brittle solids. J. Mater. Sci. 1974, 10, 113-122.

(8) Hill, R. The Mathematical Theory of Plasticity; Clarendon Press: Gloucestershire, U.K., 1950; pp 254-261.

(9) Bridgman, P. W.; Šimon, I. Effects of very high pressures on glass. J. Appl. Phys. 1953, 24, 405.

(10) Mackenzie, J. D. High-pressure effects on oxide glasses: I. Densification in rigid state. J. Am. Ceram. Soc. 1963, 46, 461.

(11) Rouxel, T.; Ji, H.; Hammouda, T.; Moréac, A. Poisson's ratio and the densification of glass under high pressure. Phys. Rev. Lett. 2008, 100, 225501.

(12) Ji, H.; Keryvin, V.; Rouxel, T.; Hammouda, T. Densification of window glass under very high pressure and its relevance to Vickers indentation. Scr. Mater. 2006, 55, 1159-1162.

(13) Polsky, C. H.; Smith, K. H.; Wolf, G. H. Effect of pressure on the absolute Raman scattering cross section of $\mathrm{SiO}_{2}$ and $\mathrm{GeO}_{2}$ glasses. J. Non-Cryst. Solids 1999, 248, 159-168.

(14) El'kin, F. S.; Brazhkin, V. V.; Khvostantsev, L. G.; Tsiok, O. B.; Lyapin, A. G. In situ study of the mechanism of formation of pressuredensified $\mathrm{SiO}_{2}$ glasses. JETP Lett. 2002, 75, 342-347.

(15) Hehlen, B. Inter-tetrahedra bond angle of permanently densified silicas extracted from their Raman spectra. J. Phys.: Condens. Matter 2010, 22, 025401.

(16) Burgin, J.; Guillon, C.; Langot, P.; Vallée, F.; Hehlen, B.; Foret, M. Vibrational modes and local order in permanently densified silica glasses: Femtosecond and Raman spectroscopy study. Phys. Rev. B 2008, 78, 184203.

(17) Poe, B. T.; Romano, C.; Zotov, N.; Cibin, G.; Marcelli, A. Compression mechanisms in aluminosilicate melts: Raman and XANES spectroscopy of glasses quenched from pressures up to 10 GPa. Chem. Geol. 2001, 174, 21-31.

(18) Gaudio, S. J.; Sen, S.; Lesher, C. E. Pressure-induced structural changes and densification of vitreous $\mathrm{MgSiO}_{3}$. Geochim. Cosmochim. Acta 2008, 72, 1222-1230.

(19) Taniguchi, T.; Ito, S. Deformation of soda-lime-silica glass under pressure and stress by molecular dynamics simulation. Phys. Chem. Glasses 2004, 45, 183-191.

(20) Deschamps, T.; Martinet, C.; Bruneel, J. L.; Champagnon, B. Soda-lime silicate glass under hydrostatic pressure and indentation: a micro-Raman study. J. Phys.: Condens. Matter 2011, 23, 035402.

(21) Silva, E.; Li, J.; Liao, D.; Subramanian, S.; Zhu, T.; Yip, S. Atomic scale chemo-mechanics of silica: Nano-rod deformation and water reaction. J. Comput.-Aided Mater. Des. 2006, 13, 135-159.

(22) Bunker, B.; Haaland, D.; Ward, K.; Michalske, T.; Smith, W.; Binkley, J.; Melius, C.; Balfe, C. Infrared spectra of edge-shared silicate tetrahedra. Surf. Sci. 1989, 210, 406-428.

(23) Wiederhorn, S. M. Influence of water vapor on crack propagation in soda-lime glass. J. Am. Ceram. Soc. 1967, 50, 407-414.

(24) Michalske, T. A.; Bunker, B. C. Slow fracture model based on strained silicate structures. J. Appl. Phys. 1984, 56, 2686-2693.

(25) Ernsberger, F. M. Role of densification in deformation of glasses under point loading role of densification in deformation of glasses under point loading. J. Am. Ceram. Soc. 1968, 51, 545-547.

(26) Koike, A.; Tomozawa, M. IR investigation of density changes of silica glass and soda-lime silicate glass caused by microhardness indentation. J. Non-Cryst. Solids 2007, 353, 2318-2327.

(27) Perriot, A.; Vandembroucq, D.; Barthel, E.; Martinez, V.; Grosvalet, L.; Martinet, C.; Champagnon, B. Raman microspectroscopic characterization of amorphous silica plastic behavior. J. Am. Ceram. Soc. 2006, 89, 596-601.

(28) Ji, H. Mecanique et physique de l'indentation du verre. Ph.D. thesis, University of Rennes 1, 2007.

(29) Satoshi, Y.; Sangleboeuf, J.-C.; Rouxel, T. Quantitative evaluation of indentation-induced densification in glass. J. Mater. Res. 2005, 20, 3404-3412.
(30) Kermouche, G.; Barthel, E.; Vandembroucq, D.; Dubujet, P. Mechanical modelling of indentation-induced densification in amorphous silica. Acta Mater. 2008, 56, 3222.

(31) Wong, L.; Suratwala, T.; Feit, M.; Miller, P.; Steele, R. The effect of $\mathrm{HF} / \mathrm{NH}_{4} \mathrm{~F}$ etching on the morphology of surface fractures on fused silica. J. Non-Cryst. Solids 2009, 355, 797-810.

(32) Ward, J. A.; Fowler, A. C.; O’Brien, S. B. Acid polishing of lead glass. J. Math. Ind. 2011, 1, 1-18.

(33) Saito, Y.; Okamoto, S.; Inomata, H.; Kurachi, J. Mechanism of the etching rate change of aluminosilicate glass in HF acid with microindentation. Appl. Surf. Sci. 2008, 255, 2290-2294.

(34) Youn, S. W.; Kang, C. G. Maskless patterning of borosilicate glass surface using nanoindentation-induced etch-hillock phenomena. J. Non-Cryst. Solids 2005, 351, 3065-3074.

(35) Saito, Y.; Okamoto, S.; Miki, A.; Inomata, H.; Hidaka, T.; Kasai, $\mathrm{H}$. Fabrication of micro-structure on glass surface using microindentation and wet etching process. Appl. Surf. Sci. 2008, 254, 72437249.

(36) Saito, Y.; Okamoto, S.; Inomata, H.; Kurachi, J.; Hidaka, T.; Kasai, $\mathrm{H}$. Micro-fabrication techniques applied to aluminosilicate glass surfaces: Micro-indentation and wet etching process. Thin Solid Films 2009, 517, 2900-2904.

(37) Judge, J. S. A Study of the dissolution of $\mathrm{SiO}_{2}$ in acidic fluoride solutions. J. Electrochem. Soc. 1971, 118, 1772-1775.

(38) Osseo-Asare, K. Etching kinetics of silicon dioxide in aqueous fluoride solutions: A surface complexation model. J. Electrochem. Soc. 1996, 143, 1339-1347.

(39) Knotte, D. M. Etching mechanism of vitreous silicon dioxide in HF-based solutions. J. Am. Chem. Soc. 2000, 122, 4345-4351.

(40) Doremus, R. H. In Glass Science; John Wiley and Sons Inc.: New York, 1994.

(41) Klapetek, P.; Nečas, D.; Anderson, C. Gwyddion, 2004; http:// gwyddion.net/. (Accessed July 9, 2012).

(42) Gimp 2.6. the GNU Image Manipulation Program, http://www. gimp.org/. (Accessed July 9, 2012).

(43) Xiao, Y.; Lasaga, A. C. Ab initio quantum mechanical studies of the kinetics and mechanisms of quartz dissolution: $\mathrm{OH}^{-}$catalysis. Geochim. Cosmochim. Acta 1996, 60, 2283-2295.

(44) Inamura, Y.; Araia, M.; Nakamuraa, T.; Otomoa, M.; Kitamurab, N.; Benningtonc, S. M.; Hannonc, A. C.; Buchenaud, U. Intermediate range structure and low-energy dynamics of densified vitreous silica. J. Non-Cryst. Solids 2001, 293-295, 389-393.

(45) Rahmani, A.; Benoit, M.; Benoit, C. Signature of small rings in the Raman spectra of normal and compressed amorphous silica: A combined classical and ab initio study. Phys. Rev. B 2003, 68, 184202.

(46) Engelhardt, G.; Michel, D. High resolution solid state NMR of silicates and zeolites; J. Wiley and Sons: Chichester, UK, 1987.

(47) Giacomazzi, L.; Umari, P.; Pasquarello, A. Medium-range structure of vitreous $\mathrm{SiO}_{2}$ obtained through first-principles investigation of vibrational spectra. Phys. Rev. B 2009, 79, 064202.

(48) Rouxel, T.; Ji, H.; Guin, J. P.; Augereau, F.; Ruffle, B. Indentation deformation mechanism in glass: Densification versus shear flow. J. Appl. Phys. 2010, 107, 094903.

(49) Xin, K.; Lambropoulos, J. C. Densification of fused silica: effects on nanoindentation. Proc. SPIE 2000, 4102, 112.

(50) Liang, J.; Suo, Z. Stress-assisted reaction at a solid-fluid interface. Interface Sci. 2001, 9, 93-104.

(51) Rusanov, A. Surface thermodynamics revisited. Surf. Sci. Rep. 2005, 58, 111-239.

(52) Chuang, T.-j.; Fuller, E. R. Extended Charles-Hillig theory for stress corrosion cracking of glass. J. Am. Ceram. Soc. 1992, 75, 540545.

(53) Nychka, J. A.; Li, D.; Alexander, B. In vitro bioactivity of $45 S 5$ bioactive glass as a function of indentation load. J. Mech. Behav. Biomed. Mater. 2008, 1, 243-251.

(54) Kese, K. O.; Rowcliffe, D. J. Nanoindentation method for measuring residual stress in brittle materials. J. Am. Ceram. Soc. 2003, $86,811-816$. 